\title{
Type 3 autoimmune polyglandular syndrome with multiple genetic alterations in a young male patient with type 1 diabetes mellitus
}

\author{
Abel Decmann ${ }^{(1)}$, Judit Tóke ${ }^{\circledR 1}$, Éva Csöregh ${ }^{\circledR 2}$, Géza Gáspárdy ${ }^{\circledR 2}$, Anikó Somogyi ${ }^{\circledR 2}$ \\ ${ }^{1}$ Department of Internal Medicine and Oncology, Faculty of Medicine, Semmelweis University, Budapest, Hungary \\ ${ }^{2}$ Department of Internal Medicine and Haematology, Faculty of Medicine, Semmelweis University, Budapest, Hungary
}

Key words: diabetes mellitus type 1; pernicious anaemia; Hashimoto's thyroiditis; homocysteine; autoimmune polyglandular syndrome

Type 1 diabetes mellitus (T1DM) is one of the most common chronic diseases in young patients. Characteristic circulating, islet-specific pancreatic autoantibodies may be present [against insulin, glutamic acid decarboxylase 65 (GAD65), zinc transporter 8 (ZnT8), 40k fragment of tyrosine phosphatase (IA2)] [1], and they can lead to insulin deficiency. Patients with T1DM can develop other organ-specific autoantibodies, causing autoimmune thyroiditis, coeliac disease, or pernicious anaemia, or patients with the mentioned diseases can often develop autoantibodies characteristic to Hashimoto's thyroiditis [2]. At least 2 organ-specific autoimmune diseases can be part of autoimmune polyendocrine/polyglandular syndromes (APS) (Tab. 1).

A 32-year-old male patient with diabetes mellitus presented to ambulatory care because of suboptimal blood sugar levels, alleged weight loss, vague low-back pain, and supposed malabsorption. The patient history contained 3 years' history of T1DM, 2 years' history of thyroid disease, and mitral and aortic valve prolapse. The patient's mother had Hashimoto's thyroiditis and myasthenia gravis. On physical examination, the patient was underweight (height $180 \mathrm{~cm}$, weight $52 \mathrm{~kg}$, BMI: $16 \mathrm{~kg} / \mathrm{m}^{2}$ ). His posture, and long limbs and fingers suggested marfanoid habitus. Antibody levels were high (Tab. 2). Based on low BMI, relatively young age, and islet-specific antibody positivity, we could confirm the diagnosis of T1DM.

Laboratory values and sonographic morphology were consistent with a euthyroid Hashimoto's thyroiditis (Fig. 1A).

The laboratory tests performed at admission showed mild, macrocytic anaemia. Vitamin B12 level
Table 1. Autoimmune polyglandular syndromes

\begin{tabular}{|c|c|c|}
\hline & Characteristic features & Additional features \\
\hline 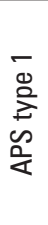 & $\begin{array}{l}\text { Two out of three: chronic } \\
\text { mucocutaneous candidiasis, } \\
\text { hypoparathyroidism, } \\
\text { autoimmune adrenal } \\
\text { insufficiency }\end{array}$ & $\begin{array}{l}\text { T1DM, pernicious anaemia, } \\
\text { hypothyroidism, ectodermal } \\
\text { dysplasia, autoimmune } \\
\text { hepatitis, primary } \\
\text { hypogonadism, alopecia, } \\
\text { malabsorption, vitiligo }\end{array}$ \\
\hline 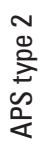 & $\begin{array}{l}\text { Autoimmune adrenal } \\
\text { insufficiency, autoimmune } \\
\text { thyroid disease } \\
\text { and/or T1DM }\end{array}$ & $\begin{array}{c}\text { Vitiligo, autoimmune hepatitis, } \\
\text { alopecia, pernicious anaemia, } \\
\text { primary hypogonadism }\end{array}$ \\
\hline$\sum_{\substack{\infty \\
\infty}}^{\infty}$ & \multicolumn{2}{|c|}{$\begin{array}{l}\text { Autoimmune thyroid disease and at least one other } \\
\text { organ-specific autoimmune disorder, e.g. T1DM, primary } \\
\text { hypogonadism, pernicious anaemia, coeliac disease, } \\
\text { vitiligo, alopecia, psoriasis that is not Addison's disease } \\
\text { or hypoparathyroidism }\end{array}$} \\
\hline
\end{tabular}

APS — autoimmune polyglandular syndrome; T1DM — type 1 diabetes mellitus

Table 2. Laboratory results

\begin{tabular}{lcc}
\hline & Value & Reference range \\
\hline Anti-GAD & $1745 \mathrm{IU} / \mathrm{mL}$ & $<10 \mathrm{IU} / \mathrm{mL}$ \\
\hline Anti-ZnT8 & $17 \mathrm{IU} / \mathrm{mL}$ & $<15 \mathrm{IU} / \mathrm{mL}$ \\
\hline ATP0 & $1196 \mathrm{U} / \mathrm{mL}$ & $<5.6 \mathrm{U} / \mathrm{mL}$ \\
\hline Vitamin B12 & $72 \mathrm{pmol} / \mathrm{L}$ & $138-652 \mathrm{pmol} / \mathrm{L}$ \\
\hline Homocysteine & $100.2 \mu \mathrm{mol} / \mathrm{L}$ & $5.4-16 \mu \mathrm{mol} / \mathrm{L}$ \\
\hline
\end{tabular}

anti-GAD — anti-glutamic acid decarboxylase antibody; anti-ZnT8 — anti-zinc transporter 8 antibody; ATPO — anti-thyroid peroxidase antibody

was below the reference range. Gastroscopy showed type A atrophic gastritis, and histological evaluation revealed severe chronic gastritis with intestinal metaplasia without $H$. pylori infection. Immunological tests 


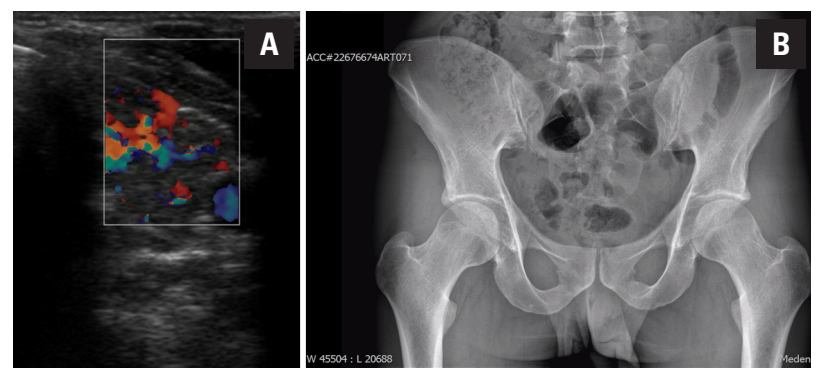

Figure 1A. Sonographic image of the hypervascularized thyroid gland. B. There is no clear sign of sacroilititis on the pelvic X-ray

were also performed. Anti-parietal cell antibodies tested positive, while antibodies against intrinsic factor were negative. Thus, the diagnosis of pernicious anaemia could be established.

The patient had vitamin B12 malabsorption. However, iron-, lipid-, protein-, and calcium/vitamin D3-metabolism were without marked alterations. Coeliac disease could also be excluded because of the negativity of antibodies against tissue transglutaminase and deamidated gliadin peptides. Gastroscopy showed no typical signs of coeliac disease in the small intestine. There were no ionic disturbances, the fasting serum cortisol level was within the normal range, and no clinical signs of hypoadrenalism were detected; therefore, we could rule out clinically manifested Addison's disease.

Concurrent Hashimoto's thyroiditis, T1DM, and pernicious anaemia, and the absence of Addison's disease and hypoparathyroidism, suggested the diagnosis of type 3 autoimmune polyendocrine syndrome. Maternal anamnesis of Hashimoto's thyroiditis and myasthenia gravis that could be diagnosed also as APS3, strengthens the diagnosis.

We performed further tests because of the marfanoid habitus and valvular prolapses of the patient. Because of the vague low-back pain and the characteristic phenotype of the patient, we performed tests to evaluate ankylosing spondylitis (AS). There was no clear sign of sacroiliitis on plain pelvic X-ray (Fig. 1B). From the 11 characteristic ankylosing spondylitis symptoms, the patient showed only 1, namely HLA-B27 positivity. According to the relevant guideline, sacroiliitis on MRI would further strengthen the diagnosis, but it is itself not diagnostic. Because of vitamin B12 deficiency, the patient's homocysteine level was measured and was found to be extremely elevated. B12 and folate-dependent enzymatic conversions are responsible for keeping homocysteine levels relatively low by conversion to methionine or cysteine. We therefore performed genetic analysis of the 2 most frequent mutations of the methylenetetrahydrofolate reductase (MTHFR) gene. We found the A1298C mutation in homozygous variant [MTHFR (methylenetetrahydrofolate reductase) C677T normal variant, MTHFR A1298C homozygous variant)]. Therefore, we concluded that the elevated homocysteine level may be explained by vitamin B12 deficiency and the patient's genetic predisposition.

The young patient has type 3 APS. The cardiovascular risk of the patient is higher because of the T1DM. Elevated homocysteine levels are associated with higher cardiovascular risk and more frequent thromboembolic events; moreover, homocysteine is an independent risk factor of cardiovascular diseases [3]. Approximately $10 \%$ of the US population are homozygous for the thermolabile variant of MTHFR (C677T), and 30\% are heterozygous for another polymorphism of MTHFR gene; A1298C is found in approximately $10 \%$ of the Caucasian population [4]. There is no clear consensus on whether reducing the homocysteine level through vitamin B12 replacement lowers the cardiovascular risk [5]. We observed genetic alteration independent of the comorbidities of type 1 diabetes mellitus.

In conclusion, in patients with type 1 diabetes mellitus and with autoimmune polyglandular syndrome, who have higher cardiovascular risk, the presence of other genetically known risk factors, such as hyperhomocysteinaemia or spondylarthritis, should be considered, in order to initiate preventive measures.

\section{Funding}

The publication of this paper was funded by the Diabetology and Metabolism Foundation (Hungary).

\section{References}

1. Mayer-Davis EJ, Kahkoska AR, Jefferies C, et al. ISPAD Clinical Practice Consensus Guidelines 2018: Definition, epidemiology, and classification of diabetes in children and adolescents. Pediatr Diabetes. 2018; 19 Suppl 27: 7-19, doi: 10.1111/pedi.12773, indexed in Pubmed: 30226024.

2. Morawiec-Szymonik E, Foltyn W, Marek B, et al. Pernicious anaemia and endocrine glands antibodies. Endokrynol Pol. 2019; 70(2): 143-150, doi: 10.5603/EP.a2018.0086, indexed in Pubmed: 30648728.

3. Zalawadiya SK, Veeranna V, Mallikethi-Reddy S, et al. Homocysteine and reclassification of cardiovascular disease risk. J Am Coll Cardiol. 2011; 58(10): 1025-1033, doi: 10.1016/j.jacc.2011.05.028, indexed in Pubmed: 21867837.

4. Botto LD, Yang Q. 5,10-Methylenetetrahydrofolate reductase gene variants and congenital anomalies: a HuGE review. Am J Epidemiol. 2000; 151(9): 862-877, doi: 10.1093/oxfordjournals.aje.a010290, indexed in Pubmed: 10791559 .

5. Clarke R, Bennett DA, Parish S, et al. MTHFR Studies Collaborative Group. Homocysteine and coronary heart disease: meta-analysis of MTHFR case-control studies, avoiding publication bias. PLoS Med. 2012; 9(2): e1001177, doi: 10.1371/journal.pmed.1001177, indexed in Pubmed: 22363213. 